\title{
Ephemeride des Planeten (433) Eros.
}

Da nach einer Mittheilung von Prof. Becker die Helligkeit des Planeten (433) Eros noch weitere Beobachtungen zulässt, habe ich aus den Elementen von Prof. E. Millesovich in Astr. Nachr. 3545 die folgende Ephemeride für $12^{\text {h }}$ mittlere Zeit Berlin gerechnet.

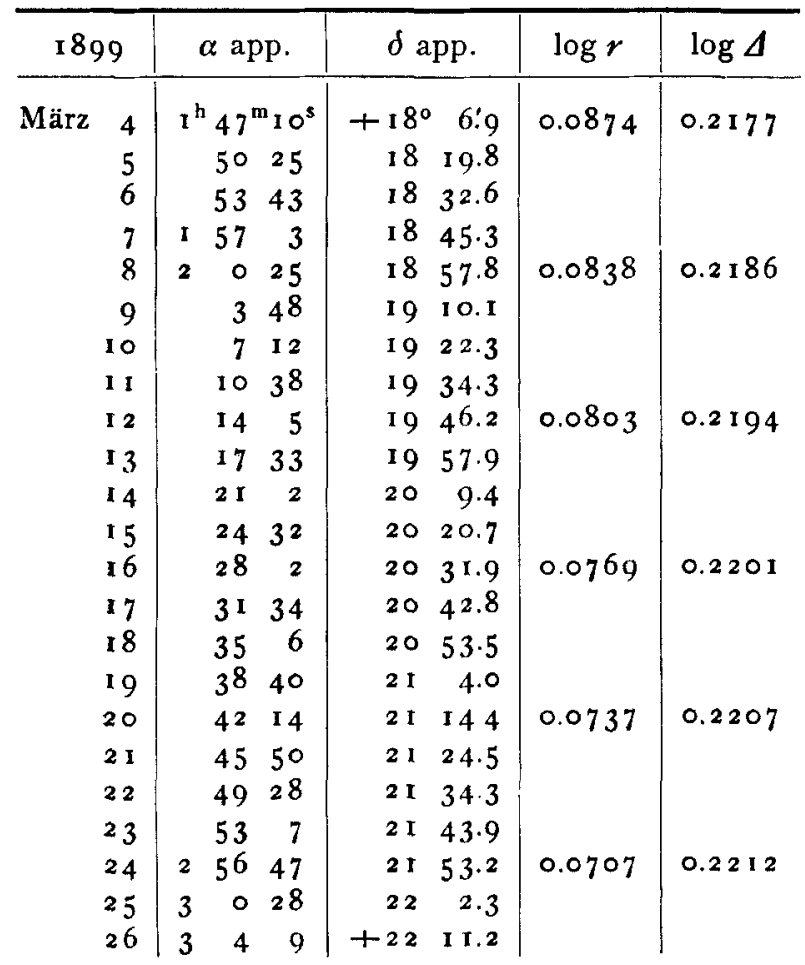

Kiel, I 899 März 3 .

\begin{tabular}{|c|c|c|c|c|c|}
\hline \multirow{2}{*}{$\frac{1899}{\text { März } 26}$} & \multicolumn{2}{|c|}{$\alpha$ app. } & $\delta$ app. & $\log r$ & $\log A$ \\
\hline & $3^{h}$ & $4^{m} 9^{s}$ & $+22^{\circ}$ II! 2 & & \\
\hline 27 & & 752 & $22 \quad 19.8$ & & \\
\hline 28 & & 135 & $22 \quad 28.2$ & 0.0680 & 0.2217 \\
\hline 29 & & $15 \quad 19$ & 2236.3 & & \\
\hline 30 & & 194 & 2244.0 & & \\
\hline $3^{I}$ & & $255^{\circ}$ & $22 \quad 51.5$ & & \\
\hline April I & & 2636 & $22 \quad 58.7$ & 0.0654 & 0.2223 \\
\hline 2 & & $30 \quad 24$ & 235.6 & & \\
\hline 3 & & $34 \quad 12$ & 2312.2 & & \\
\hline 4 & & $38 \quad 2$ & $23 \quad 18.5$ & & \\
\hline 5 & & $4 \pi \quad 53$ & 2324.6 & 0.0630 & 0.2228 \\
\hline 6 & & $45 \quad 44$ & $23 \quad 30.3$ & & \\
\hline 7 & & 4936 & $23 \quad 35.7$ & & \\
\hline 8 & & 5329 & 2340.7 & & \\
\hline 9 & 35 & 5722 & 2345.4 & 0.0610 & 0.2234 \\
\hline 10 & 4 & I 16 & 2349.8 & & \\
\hline I I & & 5 I I & 2353.8 & & \\
\hline 12 & & 97 & 2357.5 & & \\
\hline I 3 & & 3 & $24 \quad 0.9$ & $0.059 \mathrm{I}$ & 0.2239 \\
\hline I 4 & & 170 & 3.9 & & \\
\hline I 5 & & $20 \quad 57$ & 6.6 & & \\
\hline I 6 & & 2455 & $24 \quad 9.0$ & & \\
\hline 17 & 42 & 2853 & +2411.0 & 0.0576 & 0.2246 \\
\hline
\end{tabular}

F. Möller.

\section{Ephemeride des Tuttle'schen Cometen für die Wiederkehr 1899.}

Der Ephemeride liegen die folgenden Elemente zu Grunde:

Epoche 1899 Mai 14.0 mittl. Berl. Zeit.

$$
\begin{aligned}
& M=359^{\circ} 59^{\prime} 46^{\prime \prime} 7
\end{aligned}
$$

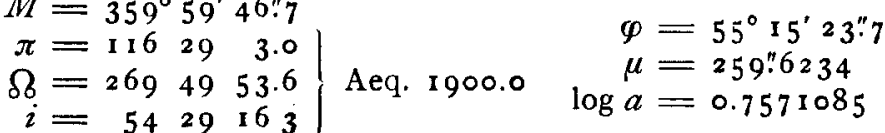

Ephemeride für I $^{\text {h }}$ M. Z. Berlin.

\begin{tabular}{|c|c|c|c|c|c|c|c|c|}
\hline 1899 & \multicolumn{3}{|c|}{$\alpha$ app. } & \multicolumn{2}{|c|}{$\delta$ app. } & $\log \Delta$ & Ab.-Zeit & $\mathrm{H}$ \\
\hline März & & $0^{h} 59^{n}$ & 58.2 & $+33^{\circ} 3$ & $3^{6^{\prime}} \times 3^{\prime \prime}$ & & & \\
\hline & & 13 & 40.5 & 332 & 279 & & & \\
\hline & & 7 & 23.4 & 331 & 1751 & 0.28043 & I $5^{\mathrm{m}} 49^{\mathrm{s}} \cdot 5$ & 0.62 \\
\hline & & I I & 6.9 & 33 & 819 & & & \\
\hline & & 14 & $5^{1.0}$ & $3^{2} 5$ & 5832 & & & \\
\hline I & & I 8 & 35.6 & $\begin{array}{ll}32 & 4\end{array}$ & 4831 & & & \\
\hline I & & 22 & 20.7 & $3^{2} 3$ & $3^{8} 14$ & 0.27824 & I $5 \quad 44.7$ & 0.66 \\
\hline I & & 26 & 6.2 & $3^{2} 2$ & $274 I$ & & & \\
\hline $\mathbf{I}$ & & 29 & 52.2 & 321 & 1652 & & & \\
\hline I & & 33 & $3^{8.6}$ & $3^{2}$ & 547 & & & \\
\hline I & & 37 & $25 \cdot 3$ & $\begin{array}{ll}3 \text { I } 5 \\
\end{array}$ & $54 \quad 25$ & 0.27617 & 1540.2 & 0.70 \\
\hline 1 & & I 41 & 12.3 & +314 & 4246 & & & \\
\hline
\end{tabular}

\begin{tabular}{|c|c|c|c|c|c|}
\hline 1899 & $\alpha$ app. & $\delta$ app. & $\log A$ & Ab.-Zeit & $\mathrm{H}$ \\
\hline März I 7 & $I^{\mathrm{h}} 44^{\mathrm{m}} 59^{\mathrm{s}} \cdot 6$ & $+3 I^{\circ} 30^{\prime} 49^{\prime \prime}$ & \multirow{6}{*}{0.27421} & \multirow{6}{*}{$\mathrm{r} 5^{\mathrm{m}} 35^{\mathrm{s}}: 8$} & \multirow{6}{*}{0.75} \\
\hline r 8 & $\begin{array}{ll}48 & 47.1\end{array}$ & $\begin{array}{lll}31 & 18 & 35\end{array}$ & & & \\
\hline I 9 & $\begin{array}{ll}52 & 34.8\end{array}$ & $\begin{array}{lll}31 & 6 & 2\end{array}$ & & & \\
\hline 20 & $156 \quad 22.6$ & $30 \quad 53$ II & & & \\
\hline 21 & $20 \quad 10.5$ & $\begin{array}{lll}30 & 40 & I\end{array}$ & & & \\
\hline 22 & 358.5 & $\begin{array}{lll}30 & 26 & 33\end{array}$ & & & \\
\hline 23 & 746.7 & 301246 & \multirow[t]{2}{*}{0.27237} & \multirow[t]{2}{*}{$15 \quad 32.4$} & \multirow[t]{2}{*}{0.80} \\
\hline 24 & I I 35.0 & $29 \quad 58 \quad 40$ & & & \\
\hline 25 & I $5 \quad 23.4$ & $2944 \quad 14$ & \multirow{4}{*}{0.27064} & \multirow{4}{*}{$\begin{array}{ll}15 & 28.7\end{array}$} & \multirow{4}{*}{0.86} \\
\hline 26 & 1911.7 & $29 \quad 2929$ & & & \\
\hline 27 & 230.0 & $\begin{array}{rrr}29 & 14 & 25\end{array}$ & & & \\
\hline 28 & $\begin{array}{ll}226 & 28.0\end{array}$ & +28590 & & & \\
\hline
\end{tabular}

